\title{
RADARSAT interferometry for Antarctic grounding-zone mapping
}

\author{
L. Gray, ${ }^{1}$ N. Short, ${ }^{2}$ R. Bindsahadler, ${ }^{3}$ I. Joughin, ${ }^{4}$ L. Padman, ${ }^{5}$ P. Vornberger, ${ }^{3}$ A. Khananian ${ }^{2}$ \\ ${ }^{1}$ Canada Centre for Remote Sensing, Ottawa, Ontario K1A 0 T7, Canada \\ ${ }^{2}$ Intermap Technologies, Ottawa, Ontario K2E 1A2, Canada \\ ${ }^{3}$ NASA Goddard Space Flight Center, Code 971 Greenbelt, MD 20771, U.S.A. \\ ${ }^{4}$ Jet Propulsion Laboratory, California Institute of Technology, 4800 Oak Grove Drive, Pasadena, CA 91109-8099, U.S.A. \\ ${ }^{5}$ Earth \&O Space Research, 1910 Fairview Ave. E., Suite 102, Seattle, WA 98102-3620, U.S.A.
}

\begin{abstract}
Satellite radar interferometry (SRI) is used to provide new information on grounding zones in areas of the eastern Ross Ice Shelf and the Filchner Ice Shelf, Antarctica. At the times of the RADARSAT SRI passes, separated by 24 days, a tidal model predicts a change in vertical displacement of the freely floating ice of $>1 \mathrm{~m}$ in both areas. The change in vertical position occurs over a $5-10 \mathrm{~km}$ flexure zone adjacent to the grounding line and would lead to a relatively high interferometric phase fringe rate. This was observed in some areas, and suitable imagery has been used to map the groundingzone position to an estimated accuracy of $1-2 \mathrm{~km}$. Results for the "ice-plain" area upstream of the Crary Ice Rise are consistent with the tidal model and improve the previous grounding-line estimates based on field surveys and Système Probatoire pour l'Observation de la Terre (SPOT) data. The results support the suggestion of increased ice grounding in this area, and show that a sub-ice-shelf water channel around the southern end of the Grary Ice Rise is unlikely. Results for the Filchner Ice Shelf also show that existing maps of the grounding zone can be refined. In particular, we identify a large ice rise close to the mouth of the Bailey Ice Stream.
\end{abstract}

\section{INTRODUGTION}

The grounding line is defined where ice flowing into a water body decouples from the glacier bed and, due to buoyancy, starts to float (Weertman, 1974). In reality, there is often a zone in which the ice is intermittently grounded depending on the state of the tide. This area is referred to as the grounding zone and is characterized in the glacial ice by narrow strand cracks at the ice surface and changes in slope. Field surveys, radioecho sounding and the analysis of optical imagery have traditionally been used to locate the grounding zone (Rose, 1979; Bindschadler and others, 1987a; Shabtaie and Bentley, 1987; Jacobel and others, 1994). The position of the grounding zone is related to ice thickness, density, local drainage patterns, sea level and bathymetry. It is important to locate the grounding line precisely because it provides a reference for monitoring changes in ice thickness and sea level (Thomas and Bentley, 1978; Rignot, 1998). Grounding-zone information is also required for sub-ice-shelf modelling of tides and currents.

Satellite radar interferometry (SRI) measures relative line-of-sight displacement between multiple synthetic aperture radar (SAR) image acquisitions. The rise and fall of ocean tides produces vertical displacement of floating ice, and under the right circumstances SRI can be used to define the boundary between the grounded and floating ice of an ice shelf. Successful mapping of grounding zones has been achieved with the European Space Agency ERS satellites (Goldstein and others, 1993; Hartl and others, 1994; Rignot, 1996). An accuracy of $500 \mathrm{~m}$ was achieved for the grounding line of the Rutford Ice Stream using two ERS-1 data acquisi- tions 6 days apart (Goldstein and others, 1993). Rignot (1996) used multiple SRI pairs and double differencing to map the grounding zone of Petermann Gletscher, Greenland, with an accuracy of $20-80 \mathrm{~m}$. The premise is that horizontal ice motion should remain constant over time, while tidal flexing will usually vary between data acquisitions. Assuming constant horizontal ice motion, double differencing can remove the effect of both the horizontal motion and topography, and the spatial extent and magnitude of the tidal influence can then be measured accurately (Rignot, 1996).

Prior to the 1997 CSA/NASA Antarctic Mapping Mission (AMM), SRI data were only available north of $79^{\circ} \mathrm{S}$. RADARSAT looked to the left during the 30 day AMM, enabling the collection of geocoded imagery to the South Pole (Jezek, 1999) and a limited SRI dataset suitable for ice-motion studies (Gray and others, 1998; Joughin and others, 1999). In this paper we use the AMM SRI data to improve grounding-zone mapping of parts of the southeast corner of the Ross Ice Shelf and the Filchner Ice Shelf .

\section{STUDY AREAS}

\section{Southeast corner of the Ross Ice Shelf}

Concerns about the stability of the West Antarctic ice sheet (Oppenheimer, 1998; Alley and Bindschadler, 2001) have led to intensive study of the ice streams in the Siple Coast region of West Antarctica. The Crary Ice Rise (CIR) is a grounded feature in the southeast region of the Ross Ice Shelf downstream from the mouth of Whillans Ice Stream. An initial 
estimate of the grounding zone made by Rose (1979) placed it relatively far inland and showed the GIR to be separated from the mainland by an area of floating ice. Both Bindschadler and others (1987a) and Shabtaie and Bentley (1987, 1988) identified areas of grounding downstream of Rose's estimate, and the latter authors proposed a grounding zone that extended much further into the ice shelf, encompassing areas close to and beside the CIR. Further work by Bindschadler (1993), based on Système Probatoire pour l'Observation de la Terre (SPOT) imagery and fieldwork, improved the grounding-line mapping in some areas, but gaps and uncertainties still existed. Because the region is known to be dynamic (Stephenson and Bindschadler, 1988; Fahnestock and others, 2000), temporal changes in the grounding zone might be anticipated. Studies of the area have shown that some sites upstream from the CIR have experienced a $50 \%$ decrease in velocity over the last three decades (Bindschadler and Vornberger, 1998) and that the "ice plain" (the lower region of Whillans Ice Stream and area upstream of the CIR) has been thickening, on average by $0.13 \pm 0.005 \mathrm{~m} \mathrm{a}^{-1}$ (Bindschadler and others, 1993). Close to and immediately upstream of the CIR, estimates of thickening have been as high as $2 \mathrm{ma}^{-1}$ (Whillans and others, 1987; Bindschadler, 1993).

\section{The Filchner Ice Shelf}

The Filchner Ice Shelf (FIS) is the eastern portion of the Filchner-Ronne Ice Shelf in the southern Weddell Sea. It periodically calves large tabular icebergs into the Weddell Sea (Gammelsrød and others, 1994) and also loses mass through the basal melting that contributes to the formation of Ice Shelf Water (ISW). The ISW plays a significant role in setting the properties of Antarctic Bottom Water which, in turn, plays a key role in global thermohaline circulation (Foldvik and others, 1985; Mikolajewicz, 1998). Ice flow into and through the FIS has been studied by Gray and others (2001) and Zhao (2001). The flow-stripe pattern visible in both radar and optical imagery matches the current velocity field of the FIS, implying that the ice-flow pattern has been relatively stable for many hundreds of years. Rignot and others (2000) show that tidal models work reasonably well along the front of the Filchner-Ronne Ice Shelf, but that tidal predictions towards the back of the ocean cavity under these ice shelves vary depending on the chosen dataset for cavity geometry and grounding line.

\section{DATA AND METHOD}

Only some of the SAR data acquisitions were repeated during the 1997 AMM, and none of the study areas had more than one pair of images suitable for interferometry. For this reason the "double-differencing" technique (Rignot, 1996) is not possible, and the grounding-zone mapping is much less accurate than is possible with multiple SRI pairs. Also, the 24 day repeat orbit of RADARSAT can be a disadvantage if there is a large velocity gradient across the grounding line. In this case there can be a loss of coherence, and other information must be used to estimate the grounding-line position. However, if coherence is maintained across the grounding zone then the 24 day image separation can be an advantage. Height differences of floating ice due to two of the most energetic tidal constituents, $M_{2}$ (period: 12.42 hours) and $O_{1}$ (period:
25.82 hours), are much larger for the 24 day pass separation than for 1 day differences, since the phase of each constituent varies by only a few degrees per day relative to the satellite pass times. Consequently, the "signal" (the dense fringe pattern associated with the change in ice height across the grounding zone) is more likely to be stronger with a 24 day separation than with 1 day.

An Antarctic tidal model (Padman and Kottmeier, 2000; Rignot and others, 2000) was used to estimate the ice-height difference for the floating ice of both study areas between the times of the RADARSAT passes. This showed that for the two pairs of passes covering the FIS, the difference in ice height was in the range $1.5-2.5 \mathrm{~m}$. For the times of the two passes covering the CIR the tidal model predicted ice-height differences of 1-2 m. Using the tidalflexure model of Vaughan (1995), these figures imply a change in vertical position downstream from the grounding zone which would produce a dense pattern of many tens of fringes at the ERS or RADARSAT frequency. The interferogram phase was unwrapped to form a two-dimensional surface reflecting the relative change in line-of-sight range between corresponding pixels in the two images. The gradient of the unwrapped phase was calculated for both the range and azimuth (along-track) directions. Note that along-track phase gradient is not a measure of the along-track changes in ice displacement: interferogram phase relates only to line-of-sight displacements, i.e. both horizontal and vertical ice movement in the range plane. Either component of the phase gradient, however, is sensitive to changes in vertical displacement, with sensitivity determined by the orientation of the grounding line. Also, estimates of coherence are reduced when the phase is changing rapidly, because the phase will change over the window used to calculate coherence. In this way images of coherence can be complementary to the phase-gradient images in estimating the position of the grounding zone.

Errors in the grounding-line positions are related to the mapping accuracy and our ability to define the groundingline position from the imagery. Despite the fact that no control points have been used and the georeferencing has been done using orbit, terrain-elevation and SAR ancillary data, the errors in the grounding-line position are still dominated by the subjective judgment made in defining the grounding line. The errors are discussed in the later sections but typically are in the range $1-2 \mathrm{~km}$. While this is much poorer than is possible with the double-differencing technique, the results are still of value considering the current uncertainty in grounding-line position and the fact that it may be many years before regions south of $\sim 79^{\circ} \mathrm{S}$ are mapped again by a SAR system suitable for double- differencing interferometry. Both the SAR imagery and the ice-surface elevation data (Bamber and Bindschadler, 1997; Jezek and others, 2000) were used to help check the estimated positions.

Figure 1 shows images of the Ross Ice Shelf study area $(\sim 100 \mathrm{~km} \times 200 \mathrm{~km})$, enlargements of which have been used to map the grounding line. The darker, somewhat jagged band at the top of the coherence image (Fig. lb) has no counterpart in the SAR amplitude image (Fig. la) and corresponds to a band of strong phase gradient visible in Figure ld and e. Interpretation of the interferometric phase (Fig. lc) is difficult at this scale. The phase of the small rectangle in the upper right of Figure lc has been enlarged in Figure 1f. This shows the dense pattern of fringes indicative of the large phase gradients expected from the change in vertical movement 


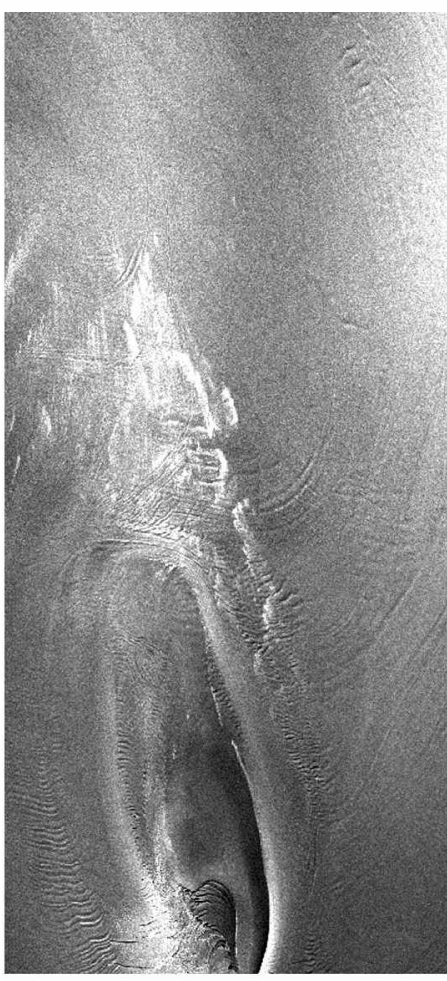

(a) SAR amplitude

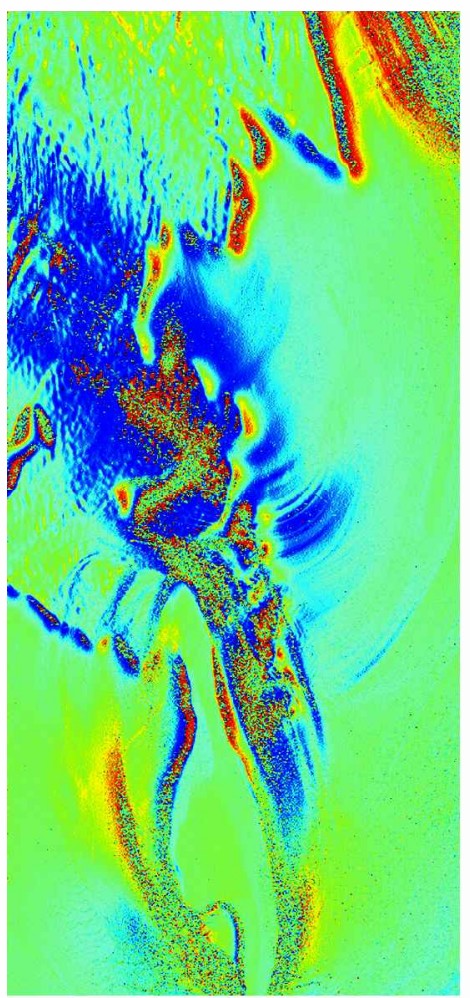

(d) Range phase gradient

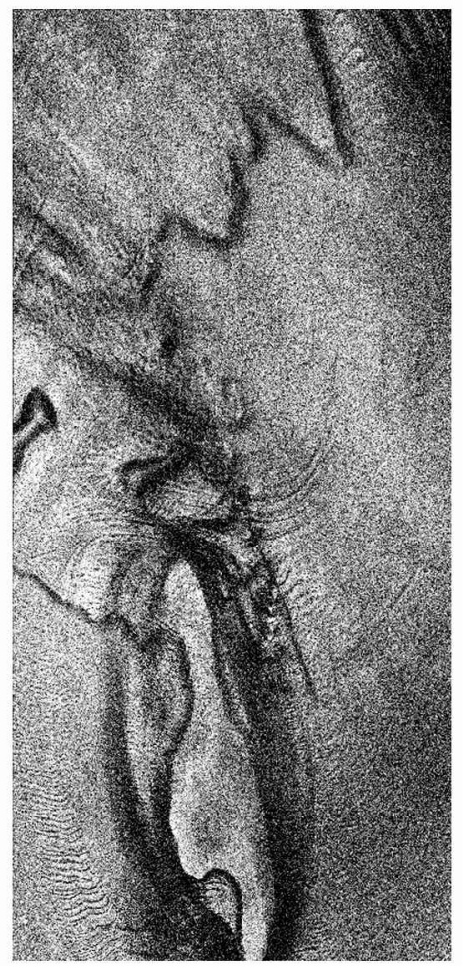

(b) Coherence

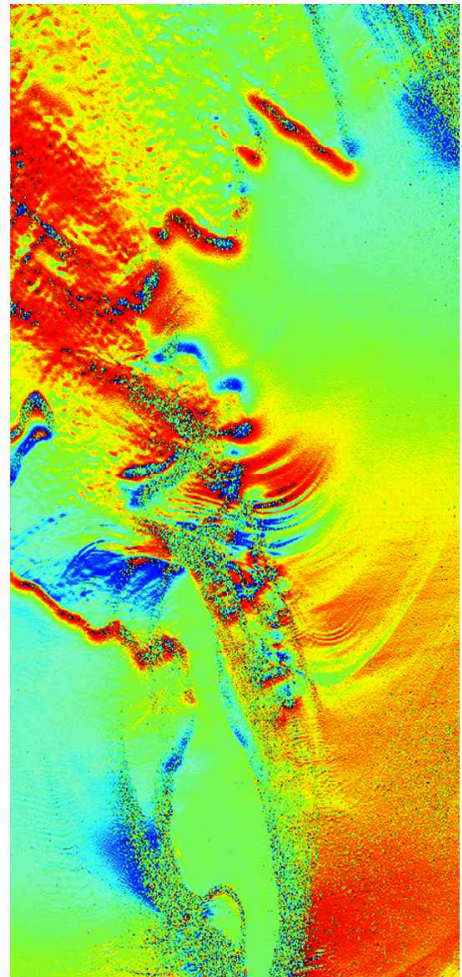

(e) Along-track gradient

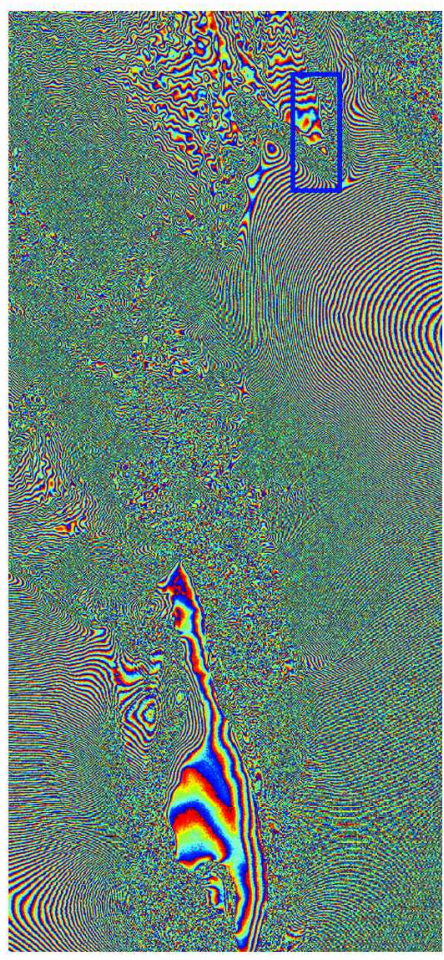

(c) Phase

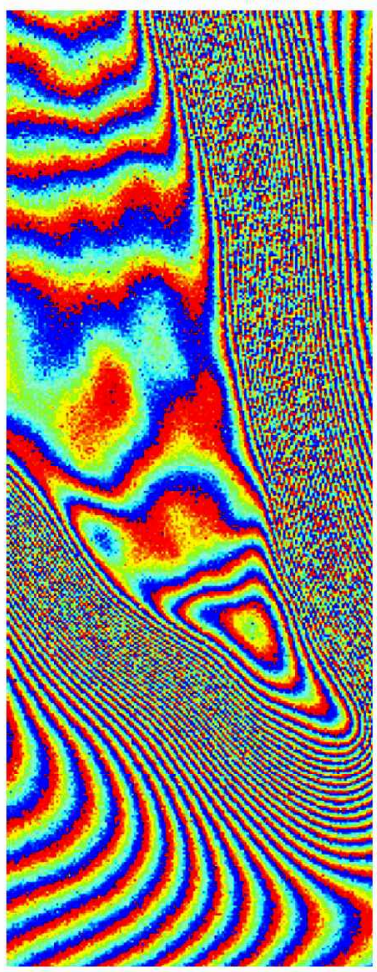

(f) Phase enlargement

Fig. 1. (a) The SAR amplitude image of an area including the CIR (lower central part of the image) and the rougher, more heavily crevassed ice just upstream. (b) The coherence for the same region. Note that the dark bands (lower coherence) beginning at the top right and left side of $(b)$ do not appear in $(a)$. These bands correspond to the regions of high phase gradients shown in $(d)$ and $(e)$. (c) The interferometric phase. ( $d, e)$ The gradients of the phase in range (horizontal) and along-track (vertical), respectively. (f) An enlargement of the phase enclosed in the box in the upper right of $(c)$.

associated with a grounding zone. The position of the grounding line is judged to be just at the upstream edge of the region of high phase gradient or associated lower coherence.

Note the smooth character of the phase-gradient image for the floating ice (centre right in Fig. ld and e) in relation to the more variable, mottled, character of the phase variations for the grounded ice (upper left). It is well known that phase variations in SRI can be related to topography and terrain motion. For this pass the interferometric baseline is such that the phase variations over the grounded ice cannot 


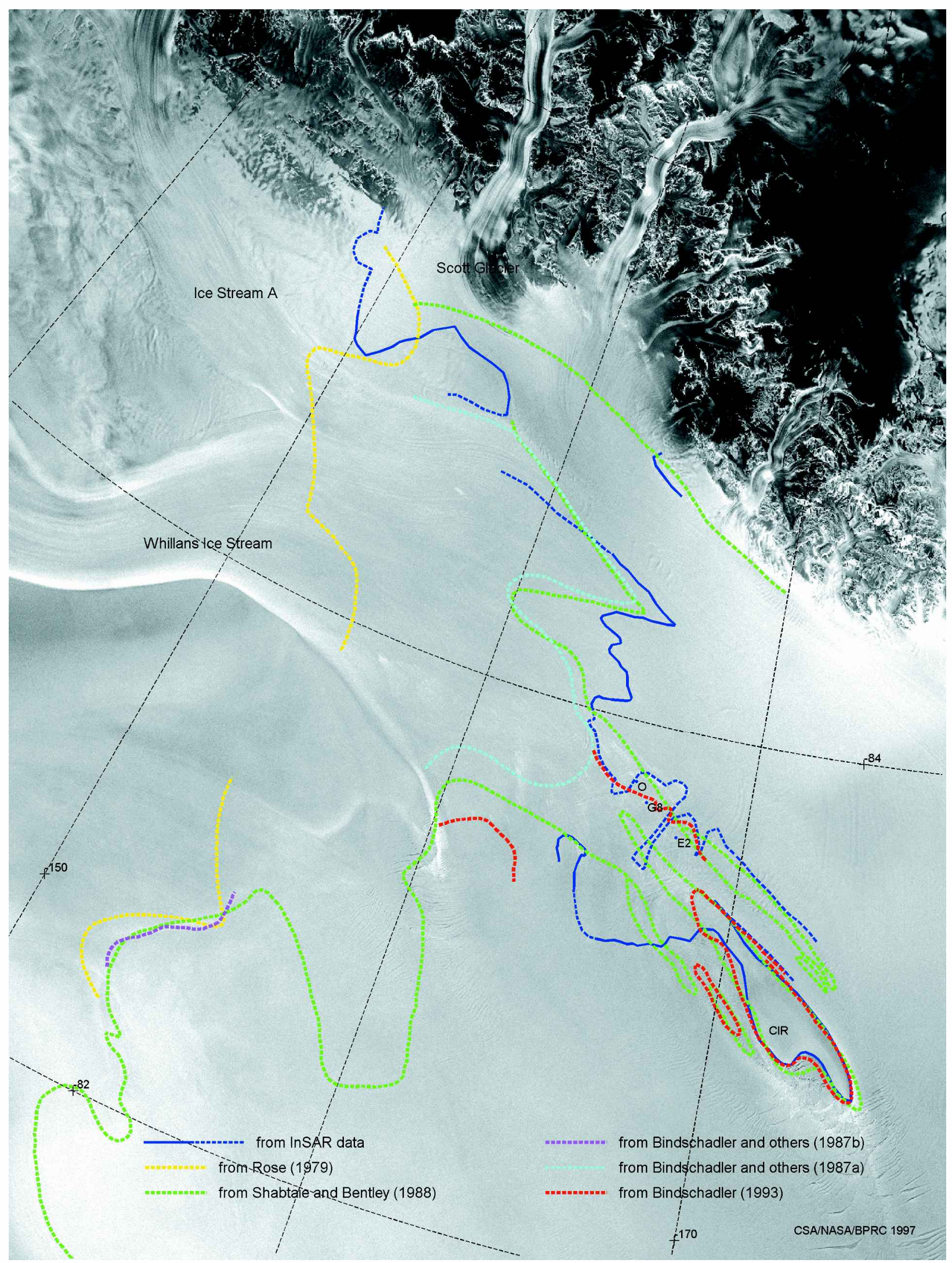

Fig. 2. Illustration of earlier grounding-zone estimates together with the position estimated from the SRI results. These data are superimposed on part of the AMM Antarctic mosaic. Blue is used to illustrate the SRI-derived grounding line, and other colors for the older estimates. A solid line indicates a 1-2 km mapping accuracy; a dashed line indicates that the interpretation is more difficult and the positional errors are unknown.

be due to topography alone but must involve variations in ice motion coupled to the variations in topography. Measurements of surface topography in this area (Bindschadler, 1993) and study of SPOT imagery over time (R. Bindschadler and P. Vornberger, unpublished information) show that the surface topography does persist at particular locations with time. Consequently, horizontal motion of the ice will induce vertical movement leading to phase modulations (Joughin and others, 1996). Bindschadler (1993) showed meter-scale surface height modulations extending over distances of a few 


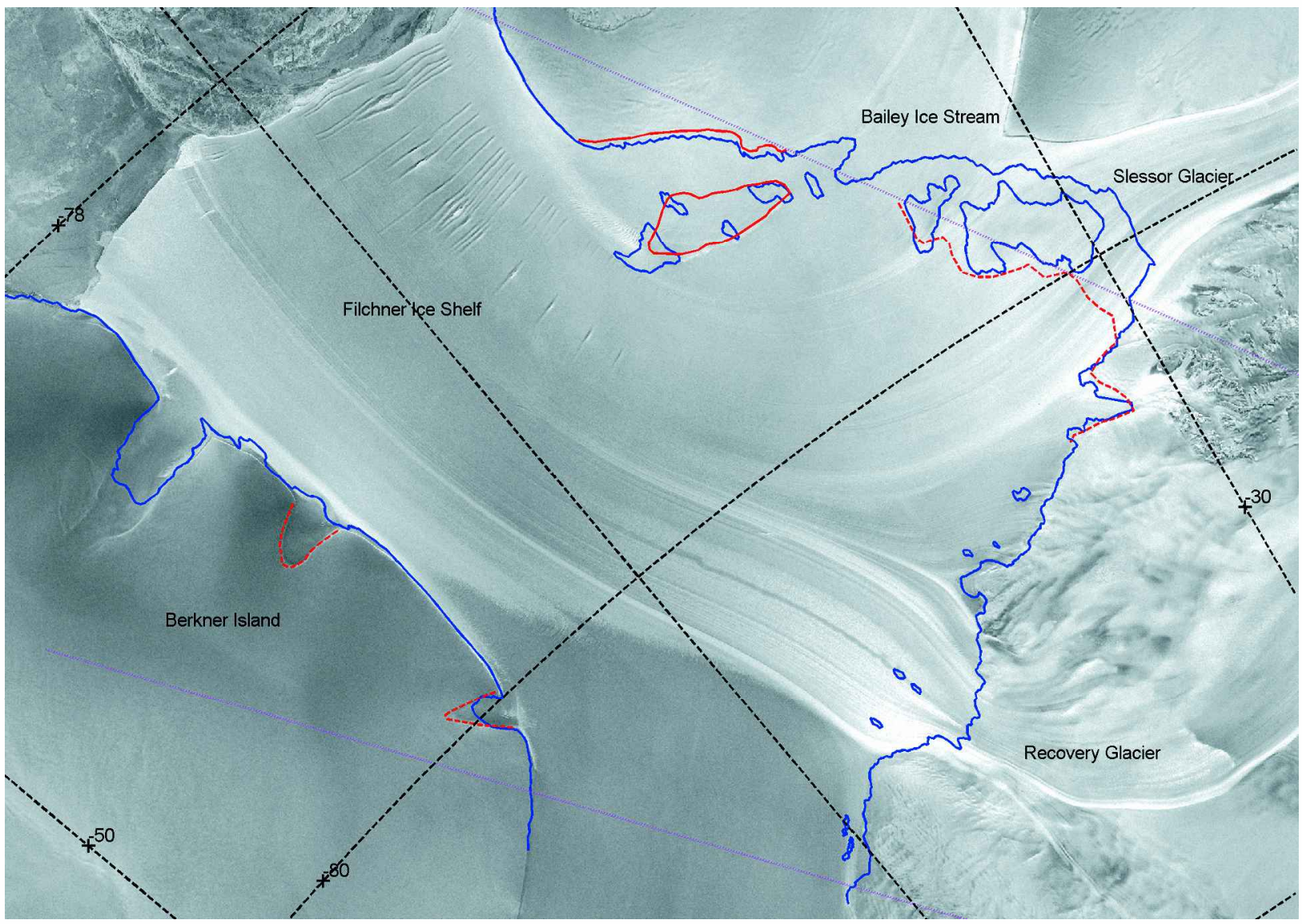

Fig. 3. The outer limits of the two RADARSAT swaths are shown as a dotted magenta line superimposed on a background image from the AMM Antarctic Mosaic. The grounding line taken from Vaughan and others (1995) is shown in blue together with the current grounding-line estimates determined from SRI in red. A solid line indicates a 1-2 km mapping accuracy; a dashed line indicates that the interpretation is more difficult and the positional errors are unknown.

kilometers. With a horizontal ice movement of around $26 \mathrm{~m}$ in the 24 days between data acquisitions (corresponding to $\sim 400 \mathrm{~m} \mathrm{a}^{-1}$ ), even the low slopes in this region will lead to vertical displacements sufficient to create the kind of phase fluctuations evident in Figure ld and e.

\section{DISGUSSION OF THE SOUTHEAST ROSS ICE SHELF RESULTS}

Figure 2 compares the previous grounding-zone estimates with those derived from the interferometric results. The blue line shows the SRI-derived grounding line. A solid line indicates a $1-2 \mathrm{~km}$ confidence in positioning the line, while the dashed blue line corresponds to much lower confidence, as discussed below. An area of grounded ice delineated by the interferometric results appears to deflect the outflow of Scott Glacier from the Transantarctic Mountains to the west. Clear fringes were observed in this region equivalent to an iceheight variation which was consistent with the tidal-model prediction (Padman and others, 2002).

Whether the ice in Ice Stream A just north of this region is grounded or not is hard to judge. While there are some fringes and the ice-surface elevation is relatively low, the exact position of the grounding line under Ice Stream A must await analysis of further data. However, the grounding zone further to the northwest can be identified. The solid blue line here reflects the results illustrated at the top of Figure 1b, d and e, and shows that the current grounding line is downstream of the earlier estimates. This may indicate an error in the earlier estimates, but it could also indicate an increase in the extent of grounded ice. Although there will be some horizontal change in ice speed across the grounding line, the tidally induced ice-height change was sufficient to create a fringe pattern which can be associated with the vertical motion. Again, the sense and approximate magnitude of the vertical movement obtained by fringe-counting was consistent with the tidal model.

In the central part of Figure lc there are regions of high phase noise (presumably due to higher shear stresses), and the grounding-line mapping is much more difficult. Clearly, the ice $\sim 50 \mathrm{~km}$ to the south of the GIR is floating and as one approaches the southwest flank of the CIR one can estimate the first area at which, possibly intermittently, grounding takes place. Consequently, the dashed blue line in this area represents an approximate estimate of the "outer" limit of ice grounding. There is also an indication of floating ice upstream of the CIR which has led to the "inlet" in the dashed line. The errors associated with the dashed line are unknown.

Previous work provided evidence of increased grounding in some areas, particularly just upstream of the CIR. Point G8 in Figure 2 was suggested to be floating in 1973 (Robertson and Bentley, 1984) but is considered grounded in Shabtaie and Bentley (1987) and Bindschadler (1993). Point O, identified by Bindschadler and others (1987b) to be floating, may now be just grounded based on the phase results. Site E2 has also been identified by Bindschadler (1993) as an area which may have shown an increase in grounding. The suggestion that the grounding zone has recently expanded to incorporate these once-floating areas is supported by the significant ice 


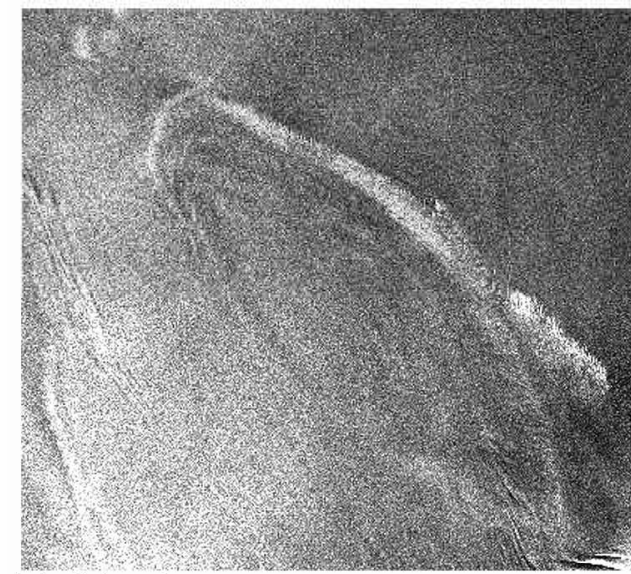

(a) SAR image

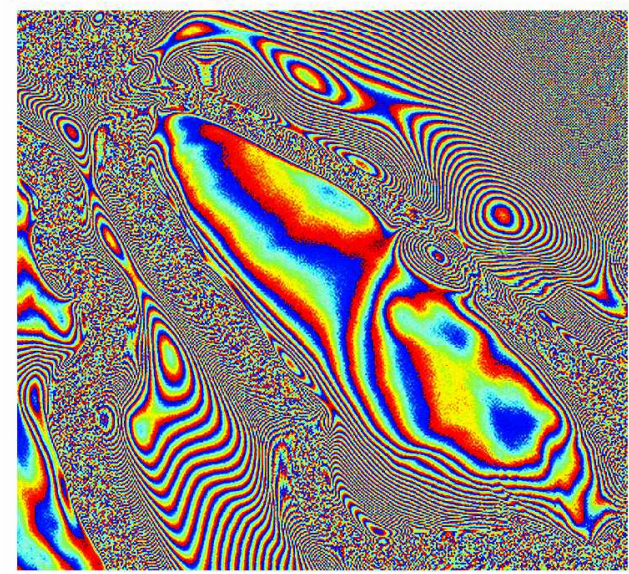

(c) Phase

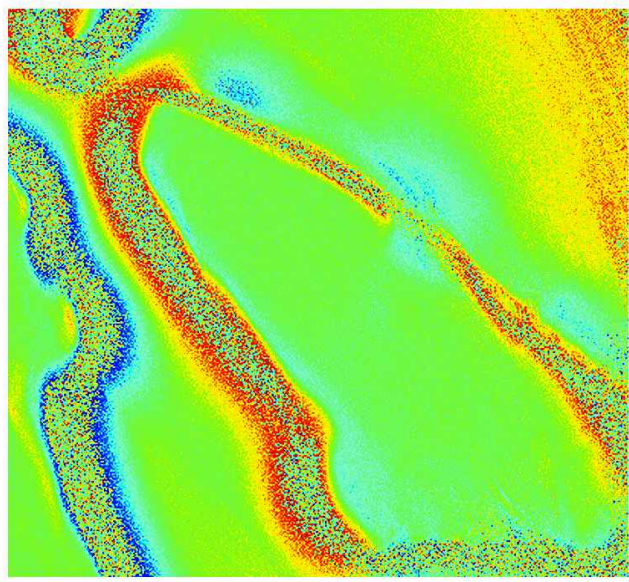

(e) Phase gradient in range

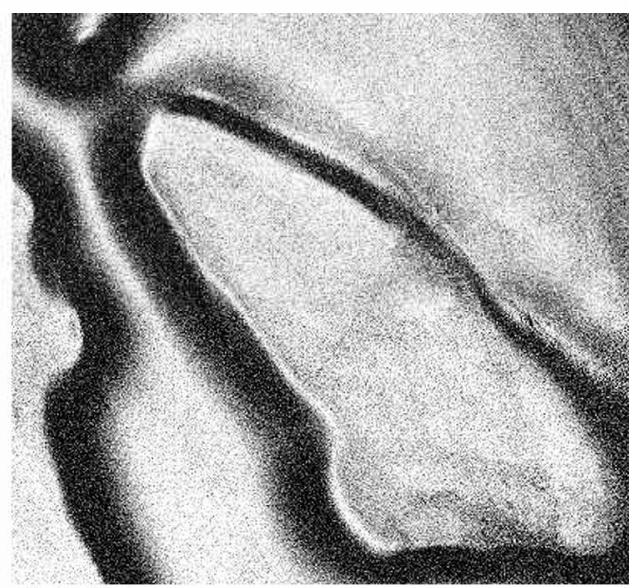

(b) Coherence

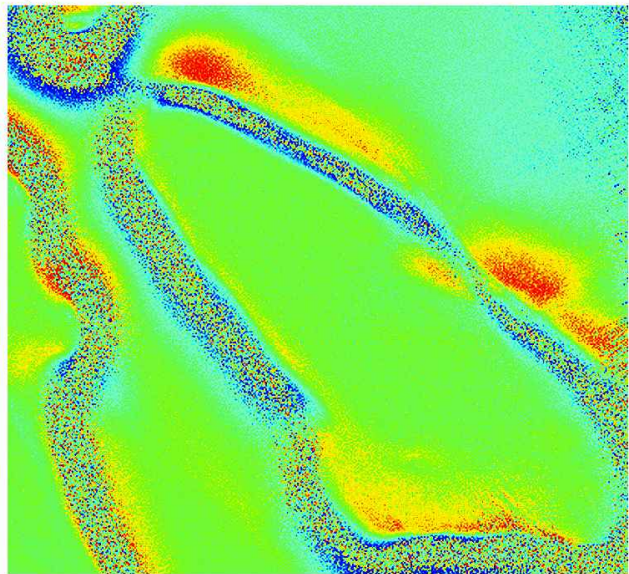

(d) Along-track phase gradient

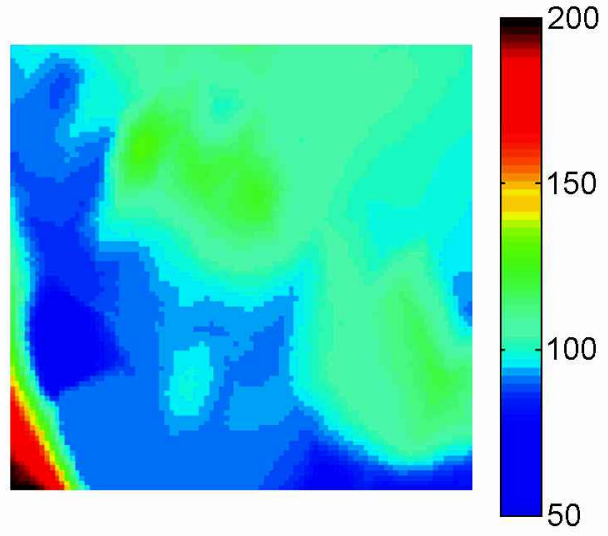

(f) Ice elevation (m)

Fig. 4. Illustration of the proposed ice rise at the outflow of the Bailey Ice Stream; (a) SAR amplitude image; (b) the coherence; (c) the interferometric phase; $(d, e)$ the phase gradients in the along-track (vertical) and range (horizontal) directions, respectively; $(f)$ ice elevation data which show a weak elevation signature supportive of the interpretation of this feature as an ice rise.

thickening experienced in this region (Bindschadler, 1993). It is well known that both the ice and bed slopes in the "ice plain" are very low, and the ice thickness is close to, but just greater than, that required for buoyancy (Shabtaie and Bentley, 1987). The possibility of a continuing increase in ice grounding is therefore consistent with both the increased ice thickness and a continuing decrease in the ice velocity (Bindschadler and Vornberger, 1998).

As the ice flows around the CIR the high strain rates, crevassing and resulting loss of coherence complicate the interpretation of the interferometric phase results. On the southwestern flank of the CIR it is difficult to map all the grounded areas. However, there does appear to be a water channel close to the CIR, consistent with the earlier data, as shown in Figure 2. The existence of a "raft" of ice moving northwards away from the CIR on the eastern flank was discussed by Bindschadler and others (1988). This region can be identified in the interferometric results, but we cannot positively confirm that there is grounded ice in this region. The existence of the grounding zone extending from the upstream end of the CIR to the west is, however, more clearly defined (Fig. 2). The integrity of this grounding zone is important to our conclusion that there does not appear to be a sub-ice water channel around the upstream end of the CIR. 


\section{DISGUSSION OF THE FIS RESULTS}

Figure 3 shows the grounding line taken from Vaughan and others (1995) in blue, together with the current groundingline estimates determined from SRI in red. The agreement is generally good, but, as shown, there are some differences. The Vaughan and others (1995) grounding-line data are mainly interpreted from the analysis of Landsat imagery. In the mouth of the Bailey Ice Stream the SRI data show the presence of a large ice rise $(\sim 50 \mathrm{~km} \times 20 \mathrm{~km})$, in contrast to several smaller features shown in the 1995 map. Figure $4 \mathrm{a}-\mathrm{f}$ show some of the results from this region supporting the current interpretation of this feature. The tidal model predicts $\sim 2 \mathrm{~m}$ height difference in freely floating ice between the overpass times, implying $\sim 60$ fringes over the tidal-flexure zone. In fact, the fringes were so dense that it was difficult to count them so that a quantitative comparison between the tidal model and the SRI results could not be made. The ice rise also has an associated weak signature in the digital elevation model (DEM) data from satellite altimetry (Jezek and others, 2000), shown in Figure 4f. Using the phase and phase-gradient data from the mouth of Slessor Glacier, the grounding line appears slightly downstream from that shown by the 1995 map. However, this is at the limit of the SRI coverage, and the area could be intermittently grounded as shown in the 1995 map. Consequently, we have shown these results as a dashed red line without any estimate of accuracy.

\section{SUMMARY}

Interferometric SAR data from the 1997 RADARSAT AMM have been used to provide new information on the grounding lines in parts of the eastern Ross Ice Shelf and the FIS. The method relies on identifying the regions of strong phase gradients that can occur in SAR interferograms of groundingzone areas due to tidally induced height change.

The new grounding-line data immediately upstream of the CIR in the southeastern sector of the Ross Ice Shelf are consistent with the previous suggestion of increased grounding in this area. These results also show that a sub-ice water channel around the southern edge of the CIR is unlikely, although such a channel may have existed in the past. Results for the FIS also show some improvements to our knowledge of the grounding line. A large ice rise is mapped at the outflow of the Bailey Ice Stream into the FIS, while the existence of several previously mapped smaller grounded features is questioned.

\section{AGKNOWLEDGEMENTS}

RADARSATdata are copyright the Canadian Space Agency (CSA) and provided by RADARSAT International and the Alaska SAR Facility. The AMM data were collected as a result of a cooperative NASA/CSA project led by K. Jezek of the Byrd Polar Research Center (BPRG), The Ohio State University. Mission planning was carried out primarily by J. Crawford at the Jet Propulsion Laboratory (JPL), Pasadena. DEMs used in this work were provided by J. Bamber and K. Jezek. The background image used in Figures 2 and 3 is the $125 \mathrm{~m}$ mosaic produced by the BPRC. K. Mattar helped with software development and processing of some of the data used in this work. The ocean tidal modeling was supported by grants to Earth \& Space Research from the U.S. National Science Foundation (NSF) Office of Polar Programs (OPP9896041) and NASA (NAG5-7790). Work at NASA Goddard
Space Flight Center was supported by NSF, while NASA supported the work at JPL. Helpful comments on the paper were provided by E. Rignot of JPL.

\section{REFERENGES}

Alley, R. B. and R. A. Bindschadler. 2001. The West Antarctic ice sheet and sealevel change. In Alley, R.B. and R.A. Bindschadler, eds. The West Antarctic ice sheet: behavior and environment. Washington, DC, American Geophysical Union, 1-11. (Antarctic Research Series 77.)

Bamber, J. L. and R. A. Bindschadler. 1997. An improved elevation dataset for climate and ice-sheet modelling: validation with satellite imagery. Ann. Glaciol., 25, 439-444.

Bindschadler, R. 1993. Siple Coast Project research of Crary Ice Rise and the mouths of Ice Streams B and C, West Antarctica: review and new perspectives. 7. Glaciol., 39(133), 538-552.

Bindschadler, R. and P. Vornberger. 1998. Changes in the West Antarctic ice sheet since 1963 from declassified satellite photography. Science, 279(5351), 689-692.

Bindschadler, R. A., S. N. Stephenson, D. R. MacAyeal and S. Shabtaie. 1987a. Ice dynamics at the mouth of Ice Stream B, Antarctica. 7. Geophys. Res., 92(B9), 8885-8894.

Bindschadler, R. A., D. R. MacAyeal and S. N. Stephenson. 1987b. Ice stream-ice shelf interaction in West Antarctica. In Van der Veen, C. J. and J. Oerlemans, eds. Dynamics of the West Antarctic ice sheet. Dordrecht, etc., D. Reidel Publishing Co., 161-180. (Glaciology and Quaternary Geology 4.)

Bindschadler, R. A., P. L. Vornberger, S. N. Stephenson, E. P. Roberts, S. Shabtaie and D. R. MacAyeal. 1988. Ice-shelf flow at the boundary of Crary Ice Rise, Antarctica. Ann. Glaciol., 11, 8-13.

Bindschadler, R., P. L. Vornberger and S. Shabtaie. 1993. The detailed net mass balance of the ice plain on Ice Stream B, Antarctica: a geographic information system approach. F. Glaciol., 39(133), 471-482.

Fahnestock, M. A., T. A. Scambos, R. A. Bindschadler and G. Kvaran. 2000. A millennium of variable ice flow recorded by the Ross Ice Shelf, Antarctica. 7. Glaciol., 46 (155), 652-664.

Foldvik, A., T. Gammelsrød, N. Slotsvik andT. Tørresen. 1985. Oceanographic conditions on the Weddell Sea shelf during the German Antarctic Expedition 1979/80. Polar Res., 3(2), 209-226.

Gammelsrød, T. and 9 others. 1994. Distribution of water masses on the continental shelf in the southern Weddell Sea. In Johannessen, O. M., R. D. Muench and J. E. Overland, eds. The polar oceans and their role in shaping the global environment: the Nansen Centennial volume. Washington, DC, American Geophysical Union, 159-176. (Geophysical Monograph 85.)

Goldstein, R. M., H. Engelhardt, B. Kamb and R. M. Frolich. 1993. Satellite radar interferometry for monitoring ice sheet motion: application to an Antarctic ice stream. Science, 262(5139), 1525-1530.

Gray, A. L., K. E. Mattar and P. W. Vachon. 1998. InSAR results from the RADARSAT Antarctic mapping mission data: estimation of data using a simple registration procedure. In Stein, T., ed. IGARSS'98. 18th International Geoscience and Remote Sensing Symposium, 6-10 July 1998, Seattle, Washington. Proceedings. Piscataway, NJ, Institute of Electrical and Electronics Engineers, 1638-1640.

Gray, A. L., N. Short, K. E. Mattar and K. C. Jezek. 2001. Velocities and ice flux of the Filchner Ice Shelf and its tributaries determined from speckle tracking interferometry. Can. F. Remote Sensing, 27(3), 193-206.

Hartl, P., K.-H. Thiel, X. Wu, C. S. M. Doake and J. Sievers. 1994. Application of SAR interferometry with ERS-1 in the Antarctic. Earth Obs. Q., 43,1-4.

Jacobel, R.W., A. E. Robinson and R. A. Bindschadler. 1994. Studies of the grounding-line location on Ice Streams D and E, Antarctica. Ann. Glaciol., 20, 39-42

Jezek, K. C. 1999. Glaciological properties of the Antarctic ice sheet from RADARSAT-1 synthetic aperture radar imagery. Ann. Glaciol., 29, 286-290.

Jezek, K. C., H. Liu, Z. Zhao and B. Li. 2000. Improving a digital elevation model of Antarctica using radar remote sensing data and GIS techniques. Polar Geogr., 23(3), 209-224.

Joughin, I., D. Winebrenner, M. Fahnestock, R. Kwok and W. Krabill. 1996. Measurement of ice-sheet topography using satellite-radar interferometry. 7. Glaciol., $42(140), 10-22$.

Joughin, I. and 7 others. 1999. Tributaries of West Antarctic ice streams revealed by RADARSAT interferometry. Science, 286(5438), 283-286

Mikolajewicz, U. 1998. Effect of meltwater input from the Antarctic ice sheet on the thermohaline circulation. Ann. Glaciol., 27, 311-315.

Oppenheimer, M. 1998. Global warming and the stability of the West Antarctic ice sheet. Nature, 393(6683), 325-332

Padman, L. and Ch. Kottmeier. 2000. High-frequency ice motion and divergence in the Weddell Sea. f. Geophys. Res., 105(19), 3379-3400.

Padman, L., H. A. Fricker, R. Coleman, S. Howard and L. Erofeeva. 2002. 
A new tide model for the Antarctic ice shelves and seas. Ann. Glaciol., 34 (see paper in this volume).

Rignot, E. 1996. Tidal motion, ice velocity and melt rate of Petermann Gletscher, Greenland, measured from radar interferometry. 7. Glaciol., 42(142), 476-485.

Rignot, E. J. 1998. Fast recession of a West Antarctic glacier. Science, 281(5376), 549-551.

Rignot, E., L. Padman, D. R. MacAyeal and M. Schmeltz. 2000. Observation of ocean tides below the Filchner and Ronne Ice Shelves, Antarctica, using synthetic aperture radar interferometry: comparison with tide model predictions. 7. Geophys. Res., 105(C8), 19,615-19,630.

Robertson, J. D. and C. R. Bentley. 1984. Seismic studies on the grid-western half of the Ross Ice Shelf: RIGGS I and RIGGS II. In Hayes, D. and C. R. Bentley, eds. The Ross Ice Shelf: glaciology and geophysics. Washing ton, DC, American Geophysical Union, 55-86. (Antarctic Research Series 42.

Rose, K. E. 1979. Characteristics of ice flow in Marie Byrd Land, Antarctica. 7. Glaciol., 24(90), 63-75.

Shabtaie, S. and C. R. Bentley. 1987. West Antarctic ice streams draining into the Ross Ice Shelf: configuration and mass balance. 7. Geophys.
Res., 92(B2), 1311-1336. (Erratum: 92(B9), 1987, p. 9451.)

Shabtaie, S. and C. R. Bentley. 1988. Ice-thickness map of the West Antarctic ice streams by radar sounding. Ann. Glaciol., 11, 126-136.

Stephenson, S. N. and R. A. Bindschadler. 1988. Observed velocity fluctuations on a major Antarctic ice stream. Nature, 334(6184), 695-697.

Thomas, R. H. and C. R. Bentley. 1978. A model for Holocene retreat of the West Antarctic ice sheet. Quat. Res., 10(2), 150-170.

Vaughan, D. G. 1995. Tidal flexure at ice shelf margins. 7. Geophys. Res., 100 (B4), 6213-6224.

Vaughan, D. G. and 9 others. 1995. Subglacial and seabed topography, ice thickness and water column thickness in the vicinity of FilchnerRonne-Shelfeis, Antarctica. Polarforschung, 64(2), 1994, 75-88.

Weertman, J. 1974. Stability of the junction of an ice sheet and an ice shelf. $\mathcal{F}$. Glaciol., 13(67), 3-11.

Whillans, I. M., J. Bolzan and S. Shabtaie. 1987. Velocity of Ice Streams B and C, Antarctica. 7. Geophys. Res., 92(B9), 8895-8902.

Zhao, Z. 2001. Surface velocities of the East Antarctic ice streams from RADARSAT-1 interferometric synthetic aperture radar data. (Ph.D. thesis, Ohio State University.) 